\title{
Clinical case of a patient with the natural flow of Fallot's tetrad
}

\author{
Rakhima Mekenbayeva $^{1}$, Anar Sarsembayeva ${ }^{1}$, Bakhytzhan Nurkeyev ${ }^{1}$, Zhazira Kursanova ${ }^{1}$, Nigina \\ Mekenbayeva $^{2}$, Arman Akseitov ${ }^{2}$
}

${ }^{1}$ Pediatric Cardiac Surgery Department, National Scientific Medical Center, Nur-Sultan city, Republic of Kazakhstan

${ }^{2}$ Astana Medical University, Nur-Sultan city, Republic of Kazakhstan

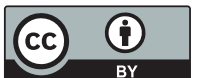

This work is licensed under a Creative Commons Attribution 4.0 International License

Received: 2018-04-03

Accepted: 2019-05-06

UDC: 616.1

\section{J Clin Med Kaz 2019; 2(52):68-71}

Corresponding Author: Rackhima Mekenbayeva, Pediatric Cardiac Surgery Department, National

Scientific Medical Center. Address: $7 \backslash 1$, Mailin street, 010001 Nur-Sultan city, Republic of Kazakhstan. Tel: +7705 485-75-81

E-mail: mrt.14@mail.ru

\section{Abstract}

The Fallot's tetrad is a common congenital heart disease that requires radical surgical correction.

Without treatment, Fallot's tetrad quickly leads to progressive right ventricular hypertrophy due to the increased resistance caused by a narrowing of the pulmonary trunk, which leads to heart failure and dilatation of the heart cavities. The Fallot's tetrad mortality rate reaches $35 \%$ in the first year of life and $50 \%$ in the first three years of life. By the age of 40 , only $5 \%$ of patients with Fallot's tetrad survive.

A unique feature of this clinical case is the natural life expectancy of a patient with congenital heart disease of Fallot's tetrad: not operated, with a large defect in the perimembranous part of the interatrial septum, in the advanced stage of progressive chronic heart failure with the development of pulmonary hypertension, right dilatation and left heart atrial, tricuspids, insufficiency of the II degree, decrease in global systolic function of the left ventricle. The patient was offered surgical treatment, explained the postoperative risks, which were assessed as high. The patient refused surgery, after which it was recommended inpatient treatment aimed at correcting chronic heart failure at the place of residence.

Keywords: congenital heart defect, Fallot's tetrad, pulmonary hypertension

\section{ТЕТРАДА ФАЛЛО ТАБИҒИ АҒЫМЫ БАР НАУҚАСТЫН КЛИНИКАЛЫК ЖАҒДАЙЫ}

Мекенбаева Р.Т., Сәрсембаева А.А., Нұркеев Б.А., Курсанова Ж.Р., Мекенбаева Н.Б., Аксеитов А.М.

'Балалар кардиохирургия бөлімі, Ұлттық ғылыми медициналық орталық, Нұр-Сұлтан қаласы, Қазақстан Республикасы

${ }^{2}$ Астана медициналық университеті, Нұр-Сұлтан қаласы, Қазақстан Республикасы

\section{тҰЖЫРЫМДАМА}

Фалло Тетрадасы - жалпы радикалды хирургиялық түзетуді талап ететін туа біткен жүрек ауруы. Емдеу болмаса, Фалло тетрадасы жүрек жетіспеушілігіне және жүрек қуыстарының кеңеюіне әкелетін өкпе таспасының тарылуынан туындаған қарсылықтың жоғарылауына байланысты прогрессивті оң жақ қарыншаның гипертрофиясына әкеледі. Өмірдің бірінші жылында Фалло тетрадасы өлімінің деңгейі 35\%-ға, ал өмірдің алғашқы үш жылында өлімнің 50\%-ына жетеді. 40 жасында, Фалло тетрадасы бар емделушілердің тек 5\% тірі қалады.

Бұл клиникалық жағдайдың бірегей ерекшелігі - бұл Фалло тетрадасы туа біткен жүрек ауруы бар науқастың табиғи өмір сүру ұзақтығы: өкпе гипертониясының дамуы, жүректің оң және сол жақ бөліктерінің дилатациясы, созылмалы жүрек жеткіліксіздігінің дамуымен прогрессивті созылмалы жүрек жетіспеушілігінің алдыңғы сатысында, интерративті септумның перимембранозды бөлігінде үлкен ақаулары бар, II дәрежелі жеткіліксіздік, сол жақ қарыншадың жаһандық систоликалық функциясының төмендеуі. Науқасқа хирургиялық ем ұсынылды, операциядан кейінгі тәуекелдер түсіндірілді, олар жоғары бағаланды.

Науқас хирургиялық операциядан бас тартты, содан кейін тұрғылықты жерінде созылмалы жүрек жеткіліксіздігін түзеуге бағытталған стационарлық ем ұсынылды.

Негізгі сөздер: туа біткен жүрек кемістігі, Фалло тетрадасы, өкпе қысымы көтерілуі

\section{КЛИНИЧЕСКИЙ СЛУЧАЙ ПАЦИЕНТА С ЕСТЕСТВЕННЫМ ТЕЧЕНИЕМ ТЕТРАДЫ ФАЛЛО}

Мекенбаева Р.Т., Сарсембаева А.А., Нуркеев Б.А., Курсанова Ж.Р., Мекенбаева Н.Б., Аксеитов А.М.

'Детское кардиохирургическое отделение, Национальный научный медицинский центр, город Нур-Султан, Республика Казахстан

${ }^{2}$ Медицинский университет Астана, город Нур-Султан, Республика Казахстан

\section{PEЗЮME}

Тетрада Фалло - часто встречающийся врожденный порок сердца, требующий радикальную оперативную коррекцию. Без лечения тетрада Фалло быстро приводит к прогрессирующей гипертросрии правого желудочка из-за повышенной резистентности, вызванной сужением легочного ствола, что приводит к сердечной недостаточности и дилатации полостей сердца. Уровень смертности при тетраде Фалло достигает 35\% в первый год жизни и 50\% смертности в первые три года жизни. К 40 годам выживают только 5\% больных с тетрадой Фалло. 
Уникальной особенностью данного клинического случая является естественная продолжительность жизни пациента с врожденным пороком сердца тетрада Фалло: не оперированный, с большим дефектом в перимембранозной части межпредсердной перегородки, в запущенной стадии прогрессирующей хронической сердечной недостаточности с развитием легочной гипертензии, дилатацией правых отделов и левого предсердия сердца, трикуспидальной недостаточностью II степени, снижением глобальной систолической фрунцци левого желудочка. Пациенту было предложено оперативное лечение, разъяснены послеоперационные риски, которые были оценены, как высокие. Пациент от оперативного вмешательства отказался, после чего было рекомендовано стационарное лечение, направленное на коррекцию хронической сердечной недостаточности, по месту жительства.

Ключевые слова: врожденный порок сердца, тетрада Фалло, легочная гипертензия

\section{Введение}

Тетрада Фалло (ТФ) - сложный врожденный порок сердца (ВПС) «синего» типа, морфологический субстрат которого составляют четыре признака: обструкция выводного отдела правого желудочка, ДМЖП, гипертрофия правого желудочка и декстрапозиция аорты [1,2]. Доля тетрады Фалло в структуре всех ВПС составляет 7-10\% и половину всех пороков цианотического типа.

Тетрада Фалло очень часто сочетается с другими аномалиями сердца: в $40 \%$ случаев - с дефектом межпредсердной перегородки (ДМПП) или открытым овальным окном (ООО), в 25\% случаев - с декстрапозицией аорты, в 3-15\% случаев - со множественными ДМЖП, в 5-12\% случаев - с аномалиями коронарного русла. У 9-17\% пациентов с тетрадой Фалло наблюдается синдром Ди Джорджи, у пациентов с тетрадой Фалло в сочетании с декстрапозицией аорты данный синдром встречается в 60$70 \%$ случаев [3].

В эмбриональном периоде пусковым механизмом тетрады Фалло служит неправильная ротация артериального конуса (против часовой стрелки), в результате возникает смещение клапана аорты правее относительно легочного. При этом аорта располагается над межжелудочковой перегородкой («аорта-всадник»). Неправильное положение аорты вызывает смещение удлиненного и суженного легочного ствола. Из-за ротации артериального конуса соединение его перегородки с межжелудочковой перегородкой затруднено, в результате образуется большой ДМЖП, в последующем, развивается дилатация правого желудочка $[4,5]$.

При ТФ течение болезни и прогноз в значительной степени определяются степенью легочного стеноза [6]:

- При естественном течении порока в течение 10 лет в живых остается 30\% пациентов.

- 25\% детей с ТФ при выраженной обструкции выводного отдела правого желудочка и легочной артерии умирают в течение первого года жизни, из них большинство на первом месяце.

- $40 \%$ больных погибают к 3 годам, 70\% - к 10 годам и 95\%- к 40 годам жизни.

Первые сообщения о ВПС, характеризующемся сочетанием ДМЖП со стенозом легочной артерии, можно найти в работах Stensen (1671), Morgagni (1762), К. А. Раухфуса (1869).

В 1888г. Fallot, систематизировав наблюдения, описал этот порок как самостоятельную нозологическую форму и дал анатомическую характеристику порока; впоследствии этот порок был назван его именем.

Выделяют четыре основных типа порока:

I тип - ТФ со стенозом легочной артерии;

II тип - ТФ с атрезией легочной артерии (7\%);

III тип - ТФ в сочетании с атриовентрикулярным септальным дефектом (6-10\%) - чаще встречается у пациентов с синдромом Дауна;
IV тип - ТФ с отсутствующим клапаном легочной артерии (5\%).

Гемодинамические изменения при тетраде Фалло обусловлены степенью препятствия к выбросу крови из правого желудочка в малый круг кровообращения и наличием ДМЖП. При ТФ отмечается значительное развитие коллатерального кровообращения между большим и малым кругом кровообращения.

\section{Клиника}

Характерными клиническимипризнаками ТФ являются развитие общей слабости после определенной физической нагрузки, головокружение, тахикардия, усиление цианоза, что связано с усилением гипоксемии из-за сброса венозной крови. При развитии одышечно-цианотических приступов состояние пациентов ухудшается. Приступы бывают самыми разнообразными по своему клиническому проявлению. У одних больных они короткие и даже не приводят к потере сознания, у других завершаются коматозным состоянием. Описаны случаи смерти или развития тяжелых форм нарушения мозгового кровообращения, возникающих вследствие одышечно-цианотического приступа.

Тактика лечения больных с ТФ предполагает хирургическое вмешательство всем пациентам независимо от возраста.

\section{Описание клинического случая}

Пациент К., 45 лет, обратился в кардиохирургическую клинику с жалобами на одышку при минимальной физической нагрузке, боли в коленных суставах, слабость, быструю утомляемость. Фото пациента представлено ниже, фотосъемка проведена с согласия больного.

Из анамнеза жизни известно, что пациент от 6-й беременности и от 4-х срочных родов. В детском возрасте перенес туберкулез легких. Кожно-венерические заболевания, вирусный гепатит, ВИЧ в семье отрицает. Наследственность: не отягощена. Аллергоанамнез: не отягощен.

Из анамнеза заболевания: впервые диагноз «ВПС» был выставлен пациенту в 8 летнем возрасте (1981 г.), в связи с участившимися жалобами на выраженную одышку при физической нагрузке. Тогда же пациент проходил обследование в г. Алматы в хирургическом центре им. Сызганова, но оперативное лечение не проведено (причины не известны), было рекомендовано дальнейшее наблюдение по месту жительства. Более пациент к помощи кардиохирургов не обращался. В течение долгого времени пациент не проходил обследования и лечения. В последние 6 лет пациент отмечает резкое ухудшение состояния в виде приступов одышки при минимальных физических нагрузках, цианоза носогубного треугольника и акроцианоза, снижения чувствительности пальцев обоих рук, потери трудоспособности. Пациент наблюдался по месту жительства, получал лечение (каптоприл 2,5 мг 1 
p/д, бисопролол 2,5 мг 1 р/д) амбулаторно. В феврале 2016г. получал стационарное лечение по месту жительства, в связи с нарастанием сердечной недостаточности (одышка при минимальной физической нагрузке, отеки на ногах, нехватка воздуха, боли в области сердца ноющего характера), получал базисную терапию, выписан в удовлетворительном состоянии. В связи с отсутствием эффекта от проводимой консервативной терапии, а также жалобами, доставляющими дискомфорт, пациент обратился в кардиохирургическую кл инику.

При настоящем обращении в клинику больной предъявляет жалобы на одышку при минимальной физической нагрузке, боли в коленных суставах, слабость, быструю утомляемость.

При физикальном обследовании состояние средней степени тяжести за счет ВПС. Сознание ясное. Рост 160 см. Вес 60 кг. ИМТ 23,4 кг/м2. Конституциональный тип

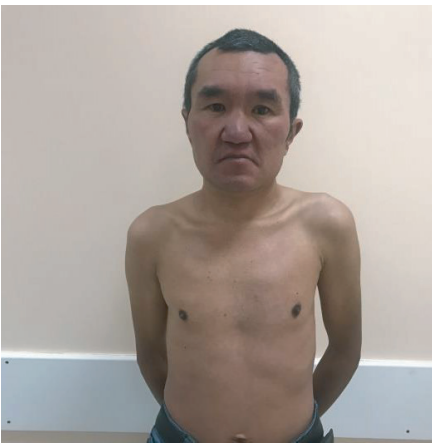

Рисунок 1

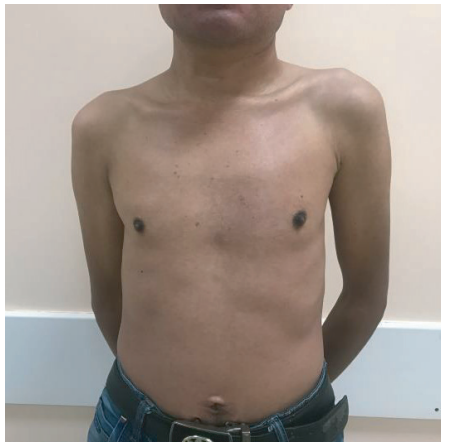

Рисунок 2
Система органов дыхания: форма грудной клетки правильная, симметричная, тип грудной клетки нормостенический, деформаций нет. Дыхание через нос свободное, ЧД 24 в минуту, при пальпации болезненных участков не выявлено. Сравнительная перкуссия - при перкуссии над симметричными участками отмечается легочный звук. Топографическая перкуссия - границы легких в пределах нормы. Аускультация - выслушивается везикулярное дыхание, равномерно проводится во все отделы, хрипов нет.

Система органов кровообращения: при осмотре области сердца пульсация верхушечного и сердечного толчков не выражена. Выражена пульсация яремных вен. Верхушечный толчок локализован в V межреберье на 1 см кнаружи от левой срединно-ключичной линии, умеренной резистентности. Систолическое дрожание по средней и верхней трети левого края грудины.

Границы относительной тупости сердца:

Правая - в IV межреберье на 1 см кнаружи правого края грудины;

Левая - в V межреберье по левой срединно-ключичной линии;

Верхняя - на уровне III ребра по левому краю грудины;

При аускультации: тоны сердца приглушены, систолический шум по левому краю грудины. ЧСС 115 в минуту. АД 110/70 мм.рт.ст.

Система органов пищеварения: язык бледно-розовый, влажный, сосочковый слой умеренно выражен, изъязвлений нет. Живот правильной формы, симметричный, вздутий нет, участвует в акте дыхания при пальпации мягкий, безболезненный. Печень не пальпируется. Размеры печени по Курлову 9-8-7. Селезенка не пальпируется. Стул в норме.
- нормостеник, отмечается слабое физическое развитие. Кожные покровы бледной окраски, выраженный акроцианоз, цианоз носогубного треугольника, малиново-фиолетовый язык. Подкожно-жировая клетчатка развита слабо, распределена равномерно. Слизистые бледной окраски, влажные. Пастозность лица, периферических отеков нет. Периферические лимфоузлы не увеличены, при пальпации безболезненны, не спаяны с окружающей тканью.

Костно-мышечно-суставная система: костный скелет имеет деформации в виде кифосколиоза грудного и поясничного отделов позвоночника (Рисунок 1, 2), пястно-фаланговые суставы кистей изменены в форме барабанных палочек, ногти в виде часовых стекол (Рисунок 3,4). Мышечная система слабо развита, тонус и сила мышц несколько снижены, при пальпации безболезненны (Рисунок 1, 2).

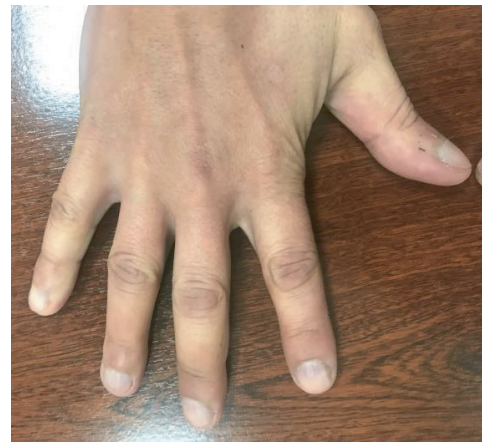

Рисунок 3

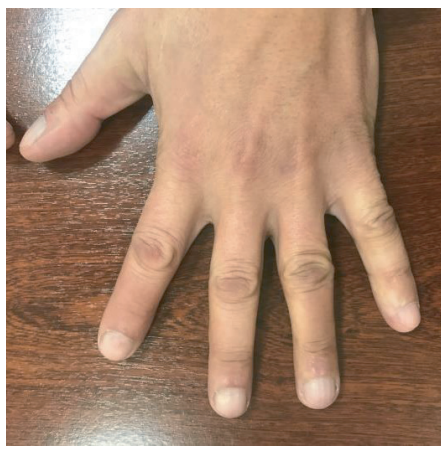

Рисунок 4
Почки не пальпируются, мочеиспускание безболезненное, свободное.

Лабораторные данные от 24.04.2018г.: общий анализ крови - гемоглобин 125 г/л, НСТ (гематокрит) 36,6 \%, цв. Показатель 0,80, RBC (общее количество эритроцитов) 4,54 10Е12/л), лейкоформула в пределах возрастной нормы (лейкоциты 6,7*109/л, нейтрофилы 3\%, сегментоядерные $42 \%$, эозинофилы $4 \%$, базофилы $2 \%$, моноциты $5 \%$, лимфоциты 44\%.), тромбоциты 308.00 тыс., СОЭ 12 мм/час.

Коагулограмма от 24.04.2018г: протромбиновое время 11.40 сек (9.40 - 12.50), Фибриноген 3,1 г/л, АЧТВ (АРТТSS) 33,3 сек, МНО 1.02 ед

Биохимический анализ крови от 24.04.2018г: показатели в пределах нормы Креатинин 68,8 мкмоль/л, Мочевина 2,45 ммоль/л, Аспартатаминотрансфераза (АСТ) 0.31 мккат/л, Аланинаминотрансфераза (АЛТ) 0.14 мккат/л, Билирубин общий 11,6 мкмоль/л, Общий белок 59,96 г/л, Глюкоза 4.21 ммоль/л (3.88 - 6.38).

При проведении ЭхоКГ исследования от 24.04.2018г выявлено: ВПС. Тетрада Фалло ДМЖП. В перимембранозной части МЖП визуализируется большой дефект р-р 2,3 см. Сброс слева направо. Дилатация правых отделов и левого предсердия сердца. Трикуспидальная недостаточность II степени. Аортальная недостаточность I степени. Глобальная систолическая функция ЛЖ снижена ФВ ЛЖ - 41\%. Диффузная гипокинезия сегментов ЛЖ и ПЖ. Высокая легочная гипертензия. Дилатация синусов Вальсальвы. Выпот в полости перикарда 200мл.

На основании вышеизложенных анамнестических, клинических данных и результатов проведенного исследования выставлен диагноз: Основное заболевание ВПС. Тетрада Фалло. Осложнения основного заболевания 
- трикуспидальная недостаточность 2 степени, высокая легочная гипертензия, СН ФК IY (NYHA).

\section{Обсуждение}

В заключение, тетрада Фалло является наиболее часто встречаемым врожденным «цианотическим» пороком сердца (11-27\%), наличие которого является абсолютным показанием для оперативного лечения. Согласно литературным данным, естественное течение данного порока подразумевает продолжительность жизни не более 40 лет, смерть пациента наступает от тромботических осложнений на фоне хронической сердечной недостаточности, а также от острой сердечной недостаточности. Наш пациент при продолжительности жизни в 45 лет и наличии признаков $\mathrm{XCH} \mathrm{имеет} \mathrm{относительно} \mathrm{удовлетворительное} \mathrm{самочувствие,}$ качество жизни пациента особо не страдает. Пациенту было предложено оперативное лечение, разъяснены послеоперационные риски, которые были оценены, как очень высокие. Однако, пациент от оперативного вмешательства отказался. Было рекомендовано стационарное лечение в условиях ЦРБ по месту жительства, направленное на коррекцию хронической сердечной недостаточности. Планируется диспансерное наблюдение данного пациента в условиях нашего стационара.

Disclosures: There is no conflict of interest for all authors.

Patient informed consent: obtained.

\section{Литература}

1. Burakovskij, L.A. Bokerija. Serdechno-sosudistaya hirurgiya (Cardiovascular surgery) [in Russian]. Moscow. 1989.

2. V.D. Ivanova. Izbrannye lektsii po operativnoi hirurgii i klinichiskoi anatomii (Selected lectures on operative surgery and clinical anatomy) [in Russian]. Samara. 2000.

3. Marshall L. Jacobs. Congenital Heart Surgery Nomenclature and Database Project: Tetralogy of Fallot. Annals of Thoracic Surgery. 2000; 69:77-82. https://doi.org/10.1016/S0003-4975(99)01239-4

4. Becker A.E., Connor M., Anderson R.H. Tetralogy of Fallot: A morphometric and geometric study. Am. J. Cardiol. 1975; 35:40212. 2. https://doi.org/10.1016/0002-9149(75)90034-X

5. Bokerija L.A., Shatalov K.V. PEdiatricheskaya kardiohirurgiya (Pediatric heart surgery) [in Russian]. M. 1996.

6. Gatzoulis M.A., Balaji S., Webber S.A. et al. Risk factors for arrhythmia and sudden cardiac death late after repair of tetralogy of Fallot: a multicentre study. Lancet. 2000; 356: 975- 81. https://doi.org/10.1016/S0140-6736(00)02714-8

How to cite this article: Rakhima Mekenbayeva, Anar Sarsembayeva, Bakhytzhan Nurkeyev, Zhazira Kursanova, Nigina Mekenbayeva, Arman Akseitov. Clinical case of a patient with the natural flow of Fallot〉s tetrad [in Russian]. J Clin Med Kaz. 2019; 2(52):68-71 